\title{
DEASHING OF COAL LIQUIDS BY SONICALLY ASSISTED FILTRATION
}

\author{
Bogdan J. Slomka \\ Fossil Energy Program \\ Ames Laboratory, Iowa State University \\ Ames, IA 50011
}

\section{INTRODUCTION}

This project seeks to improve the effectiveness and reduce the cost of coal liquefaction by novel applications of sonic and ultrasonic energy. The specific purpose of this project is to develop and improve means for the economical removal of dispersed solid particles of ash, unreacted coal, and spent catalyst from direct and indirect coal liquefaction resids by using sonic or ultrasonic waves. Product streams containing solids are generated in both direct and indirect coal liquefaction processes. Direct coal liquefaction processes generate liquid products which contain solids including coal-originated mineral matter, unreacted coal, and spent dispersed catalyst. The removal of these solids from a product stream is one of the most difficult problems in direct coal liquefaction processes. In the existing direct liquefaction processes, the liquefaction reactor(s) effluent is distilled to recover valuable product fractions before the solids are separated from remaining liquids. In consequence, the solids are concentrated in the distillation bottom fractions which are difficult to filter due to their high viscosity. The problem is aggravated by the fact that the solids are predominantly present as micron-sized particles. Removal of solids from coal liquefaction products can be accomplished in several ways. Conventional filtration used in early liquefaction technologies was mechanically troublesome and proved inefficient for processes producing high concentrations of solids in coal liquefaction products of high viscosity, e.g., SRC-I. Efforts were made to improve sedimentation and filtration rates in the deashing of coal liquids through partial precipitation of asphaltenes ${ }^{1,2}$ and using electric fields ${ }^{3}$. However, no substantial process improvements resulted for the coal liquefaction technology at the time. During the seventies, two other operations for rejecting solids from coal liquefaction product streams were introduced, namely, antisolvent deashing ${ }^{4}$, implemented by Lummus in a two-stage liquefaction process, and KerrMcGee's critical solvent deashing ${ }^{5}$ which was employed at the Wilsonville coal liquefaction facility for solids rejection ${ }^{6}$. However, it was reported that up to $30 \%$ by weight of the feed could be lost in the rejected stream ${ }^{2,7}$. At present, Hydrocarbon Research Inc. uses improved filtration of atmospheric distillation resids in a catalytic twostage direct coal liquefaction process ${ }^{8}$. Other developments ${ }^{9}$ indicate that advanced techniques of solid/liquid separation, e.g., crossflow filtration, could further improve the separation of solids from coal liquefaction products. It also has been suggested ${ }^{10}$ that acoustic, electric, and magnetic fields can prevent filter clogging and membrane fouling during crossflow filtration of suspensions. Mechanisms at work include turbulence from cavitation, microstreaming effects and viscosity reduction due to localized heating. Increased filtrate fluxes result from insonation of filtration media during filtration. Crossflow filtration is suitable for continuous flow operation and, when coupled with a sonic or ultrasonic field, may constitute a solution to operational problems of solids separation in coal liquefaction. However, for the efficient and trouble-free operation of crossflow filters the problems arising from dealing with highly viscous coal liquefaction resids need to be avoided. Either crossflow filters suitable for work at elevated temperatures at reduced resid viscosity should be used or the coal liquefaction process network should be modified to allow for dilution of resids using a distillate fraction, e.g., naphtha, diesel oil, etc., to reduce the viscosity of resids. As perhaps even a more practical alternative, field-assisted crossflow filtration of the reactor's effluent stream prior to the distillation step should be considered. Such an approach will circumvent the more difficult separation of fine and ultrafine solids from highly viscous coal liquefaction resids. 


\section{DISCLAIMER}

This report was prepared as an account of work sponsored by an agency of the United States Government. Neither the United States Government nor any agency thereof, nor any of their employees, make any warranty, express or implied, or assumes any legal liability or responsibility for the accuracy, completeness, or usefulness of any information, apparatus, product, or process disclosed, or represents that its use would not infringe privately owned rights. Reference herein to any specific commercial product, process, or service by trade name, trademark, manufacturer, or otherwise does not necessarily constitute or imply its endorsement, recommendation, or favoring by the United States Government or any agency thereof. The views and opinions of authors expressed herein do not necessarily state or reflect those of the United States Government or any agency thereof. 


\section{DISCLAIMER}

Portions of this document may be illegible in electronic image products. Images are produced from the best available original document. 


\section{EXPERIMENTAL}

Liquefaction Resid Characteristics. An atmospheric flashed bottoms stream from Wilsonville Run No. 260 was used in the deashing tests. The V-1067 resid sample (boiling above $850^{\circ} \mathrm{F}$, specific gravity 1.24 ) represents the ashy second-stage product stream which was recycled after partial deashing in the Close-Coupled Integrated TwoStage Liquefaction process. The resid typically contained $10.1 \%$ wt. ash, $30.1 \%$ tetrahydrofuran (THF)-insoluble solids, 2.0\% THF-soluble and toluene-insoluble preasphaltenes, $21.1 \%$ asphaltenes and $46.9 \%$ hexane-soluble oil component by weight. The THF-insoluble solids isolated from the resid were analyzed for particle size distribution by wet screening using THF-water mixtures as dispersing liquids. Analyses have shown that the largest particles are about 300 microns in diameter and that $59.5 \%$ by weight of the solids are smaller than 5 microns. Based on laser diffraction measurements, it was estimated that $42.9 \%$ by weight of the solids is smaller than 1.9 microns in diameter.

Crossflow Filtration Apparatus. A state-of-the-art crossflow filter utilizing 2-micron porosity stainless steel tubes as the filtration medium was built and used in the deashing tests. The crossflow filter was coupled with a 650-watt computer-based variablefrequency sonic transducer to radiate sonic waves inside the crossflow filter directly exposing the filter elements to the sonic field. Figure 1 shows the configuration of the crossflow filter apparatus. Sonic waves were radiated parallel to the filtering surfaces of the crossflow filter. This feature was incorporated in the design of the crossflow filter after earlier, less successful, experiments in which in-situ sonic waves were radiated at a right angle to the filtering surface. In this way, the build-up of solids at the filter medium, often resulting in severe clogging, was eliminated possibly due to the sonically generated rapid movement of fluid parallel to the filtering surface. Detrimental fixing of solid particles in the pores of the filter medium due to the action of high-intensity sound was found to be minimal.

\section{RESULTS AND DISCUSSION}

Crossflow Filtration. In this series of tests, the V-1067 resid, diluted with No. 2 fuel oil (1:3 by vol.), was used as the feed. A $5-\mathrm{kHz}$ pulsed sound at 650 watts was used for the insonation according to a preprogrammed sequence of 5 pulses per second. Each pulse was 40-cycles long, i.e., 8 milliseconds. Throughout the duration of filtration, samples of filtrate and of circulated slurry were collected for ash and solids content analyses. The filtrate flow rate was also measured as a function of filtration time. The reference test was performed in exactly the same manner except the sonic transducer was not energized. Table 1 and Figure 2 show the effect of $5-\mathrm{kHz}$ sonic treatment on the filtrate flow rate and filtrate ash content as a function of filtration time. Solids-free and ashless filtrates were obtained in both cases, with and without the sonic energy present during filtration. A clear beneficial effect of sonic waves is evident from the comparison of the filtrate flow rates. In the presence of $5-\mathrm{kHz}$ sonic waves applied in-situ, the filtrate flow rate was greater than that of the reference test by a factor of up to 2.74 . Total filtrate volumes collected after 90 -minute filtrations were 1.25 and 2.60 liters for the reference and the $5-\mathrm{kHz}$ test, respectively. The increased filtration performance due to in-situ insonation of the crossflow filter is also confirmed by the increased solids and ash contents of the circulated slurry as shown in Table 2 and Figure 3. Based on these unoptimized bench-scale crossflow filtration tests, and assuming the cost of electricity at $\$ 0.07 / \mathrm{kwh}$, the operating cost of sonic treatment was calculated to be $1.70 \$ / \mathrm{bbl}$ of filtrate.

Batch Filtrations. Reference Tests. The remaining solids concentrates from continuous cross-flow filtration experiments still contain from 70 to $80 \%$ by weight of hexane-soluble oil components. To test further processing options for the solids concentrates, two samples of concentrate containing $77.6 \%$ of oil by weight were subjected to conventional batch filtration on Whatman No. 5 filter discs using vacuum at room temperature. Table 3 shows the results of solubility analyses by Soxhlet extraction using n-hexane, toluene, and 
THF, for cakes from two parallel batch filtrations, Cake I and Cake II. For comparison, solubility analyses of the as-received V-1067 resid and the solids concentrate are included. The oil and asphaltene contents of the filtration cakes are significantly reduced compared to oil and asphaltene contents of the V-1067 resid, while the percent of THF insolubles and percent preasphaltenes both have increased. Up to 88-hour long filtrations produced ashless filtrates and filtration cakes which appeared dry but still contained approximately $33 \%$ by weight of hexane-soluble oil.

Sonically Assisted Batch Filtrations. Three batch filtrations of the solids concentrate were conducted at room temperature. Whatman No. 5 filter paper was used as the filter medium. A brief description of the test procedure is as follows. A well stirred sample of the solids concentrate was placed in a filtration funnel and the excess fuel oil was filtered out by applying vacuum. As soon as air broke through the filter cake, a $20-\mathrm{kHz}$ sonic probe was placed in contact with the cake and energized at 250 watts using a pulsed mode of operation at $80 \%$ duty cycle. Throughout the entire time of insonation, the probe was slightly pressed against the surface of the filter cake to ensure a good contact of probe with the surface of the cake. The cake rapidly liquified in the presence of sonic energy resulting in an additional amount of oil passing through the filter and a dry and compact cake. The oil filtrate was found to contain no solids or ash. During the insonation, the filtration cakes released a significant amount of oil vapors and possibly products of a decomposition reaction. Cake temperatures as high as $170^{\circ} \mathrm{C}$ were measured at the cake surface immediately after completion of insonations. It is worth noting that these high temperature increases of diluted V-1067 resid did not occur in earlier tests with liquid suspensions of V-1067 in No. 2 fuel oil, despite an intense acoustic cavitation taking place within the suspension. Possibly, the solids loading of the suspension must be above a certain threshold for efficient absorption of sonic energy. For a V-1067 resid and No. 2 fuel oil mixture, this solids loading threshold is at about $50 \%$ solids by weight.

Table 3 shows the solubility analyses of filtration cakes; cake 3 through 5 were insonated for 5,10 , and 20 minutes. As the insonation time increased the oil content of the filtration cake decreased while the THF insolubles and preasphaltenes contents both increased. It is evident that more oil can be recovered from solids concentrates by using sonic energy. The effect of insonation on the rate of filtration is dramatic. The analysis of the filtration cake insonated for only 10 minutes showed an oil content of $24.3 \%$ while the 88 -hour reference tests without insonation produced cakes containing 32.0 and $33.5 \%$ of oil by weight. This corresponds to an over 600 -fold increase in the average filtration rate. Little further improvement in the quality of the filtered solids was achieved by prolonging the insonation to 20 minutes.

\section{ACKNOWLEDGEMENTS}

This project has been funded by U.S. Department of Energy through Pittsburgh Energy Technology Center. Ames Laboratory is operated for the U.S. DOE by Iowa State University under Contract No. W-7405-ENG-82.

\section{REFERENCES}

1. Verhoff, F.H., Lui, S.S. and J.D. Henry, Jr., Can. J. Chem. Eng., 1978, 56, 504.

2. Gorin, E., Kulik, C.J., and Lebowitz, H.E., Ind. Eng. Chem. Proc. Des. Dev, 1977, 16(1), 102-107.

3. Lee, C.H., Gidaspow, D. and D. Wasan, Ind. Eng. Chem. Fundamentals., 1980, 12(2), 166.

4. Peluso, M. and D.F. Ogren, Chem. Eng. Progr., 1979, 6, 41.

5. Adams, R.M., Knebel, A.H. and D.E. Rhodes, Chem, Eng. Progr., 1979, 6, 44.

6. Gollakota, S.V., Davies, O.L., Vimalchand, P., Lee, J.M. and C.E. Cantrell, Direct Liquefaction Contractors' Review Conference, Sept. 24-26, 1990, Pittsburgh, PA.

7. Gorin, E., Kulik, C.J., and Lebowitz, H.E., Ind. Eng. Chem. Proc. Des. Dev, 1977, 16(1), 95-102.

8. Comolli, A.G., DOE Liquefaction Contractors' Review Conference Proceedings, Pittsburgh, PA, September 22-24, 1992, pp. 97-105. 
9. Tarleton, E.S., Filtration and Separation, May/June 1992, pp. 246-252.

10. Wakeman, R.J. and E.S. Tarleton, Trans. Ins. Chem. Eng., 1991, Vol. 69, Part A, pp. 386397.

Table 1. Sonically Enhanced Filtration of V-1067 Coal Liquefaction Resid. Filtration Rates and Filtrate Ash Contents.

\begin{tabular}{lcccll}
$\begin{array}{l}\text { Filtration } \\
\text { Time }\end{array}$ & \multicolumn{2}{c}{ REFERENCE } & \multicolumn{2}{c}{ 5-kHz SOUND } & FLOW RATE \\
(min.) & $\begin{array}{c}\text { Flow Rate } \\
\text { (ml/min.) }\end{array}$ & $\begin{array}{l}\text { \% Ash } \\
\text { (\% wt.) }\end{array}$ & $\begin{array}{c}\text { Flow Rate } \\
\text { (ml/min.) }\end{array}$ & $\begin{array}{l}\text { \% Ash } \\
\text { (\% wt.) }\end{array}$ & RATIO \\
2 & & & & & \\
5 & 80.0 & - & 83.0 & - & 1.04 \\
7 & - & - & 45.8 & - & - \\
9 & 42.9 & - & - & - & - \\
10 & 31.2 & - & - & - & - \\
15 & - & 0.000 & 39.5 & 0.000 & - \\
20 & 18.1 & 0.000 & - & 0.000 & - \\
25 & - & - & 35.7 & - & - \\
30 & 14.3 & - & - & - & - \\
40 & 13.9 & 0.000 & 31.2 & 0.000 & 2.24 \\
60 & 10.3 & - & 23.4 & - & 2.27 \\
90 & 8.7 & 0.000 & 20.5 & 0.000 & 2.36 \\
& 7.3 & 0.000 & 20.0 & 0.000 & 2.74 \\
\hline
\end{tabular}

Table 2. Sonically Enhanced Filtration of V-1067 Coal Liquefaction Resid. Slurry Ash and Solids Contents (n-Hexane Insoluble Matter).

\begin{tabular}{lccccl} 
Filtration & \multicolumn{2}{c}{ REFERENCE } & \multicolumn{2}{c}{ 5-kHz SOUND } & FLOW RATE \\
$\begin{array}{l}\text { Time } \\
\text { (min.) }\end{array}$ & $\begin{array}{c}\text { \% Solids } \\
\text { (\% wt.) }\end{array}$ & $\begin{array}{c}\text { \% Ash } \\
\text { (\% wt.) }\end{array}$ & $\begin{array}{c}\text { \% Solids } \\
\text { (\% wt.) }\end{array}$ & $\begin{array}{l}\text { \% Ash } \\
\text { (\% wt.) }\end{array}$ & RATIO \\
0 & & & & & \\
10 & 8.24 & 1.55 & 8.14 & 1.58 & 0.98 \\
20 & 7.32 & - & 8.61 & - & 1.18 \\
30 & 7.46 & - & 10.22 & - & 1.37 \\
40 & 7.96 & - & 12.20 & - & 1.53 \\
60 & 12.78 & - & - & - & - \\
90 & - & 1.74 & 15.77 & 1.87 & - \\
& 15.32 & 1.77 & 17.32 & 1.93 & 1.13
\end{tabular}

Table 3. Solubility Analysis of Filter Cakes From Batch Filtrations of Solids Concentrate.

Weight Percent

\begin{tabular}{|c|c|c|c|c|c|c|c|}
\hline \multicolumn{8}{|c|}{ Weight Percent } \\
\hline & V-1067 & Conc. & Cake 1 & Cake 2 & Cake 3 & Cake 4 & Cake 5 \\
\hline Insonation time & - & - & $0 \mathrm{~min}$. & $0 \mathrm{~min}$. & $5 \mathrm{~min}$. & $10 \mathrm{~min}$. & $20 \mathrm{~min}$ \\
\hline Filtration time: & - & - & 88 hrs & $88 \mathrm{hrs}$ & $5 \mathrm{~min}$. & $10 \mathrm{~min}$. & $20 \mathrm{~min}$ \\
\hline \multicolumn{8}{|l|}{ Solubility Class } \\
\hline Oil & 46.9 & 77.6 & 33.5 & 32.0 & 36.9 & 24.3 & 24.1 \\
\hline Asphaltenes & 21.1 & 7.2 & 13.8 & 14.6 & 14.2 & 15.5 & 15.5 \\
\hline Preasphaltenes & 4.3 & 3.4 & 17.9 & 17.6 & 17.5 & 22.0 & 22.1 \\
\hline THF Insolubles & 27.7 & 11.8 & 34.8 & 35.0 & 31.4 & 38.2 & 38.2 \\
\hline & 100.0 & 99.1 & 100.0 & 99.2 & 100.0 & 100.0 & $\overline{99.9}$ \\
\hline
\end{tabular}




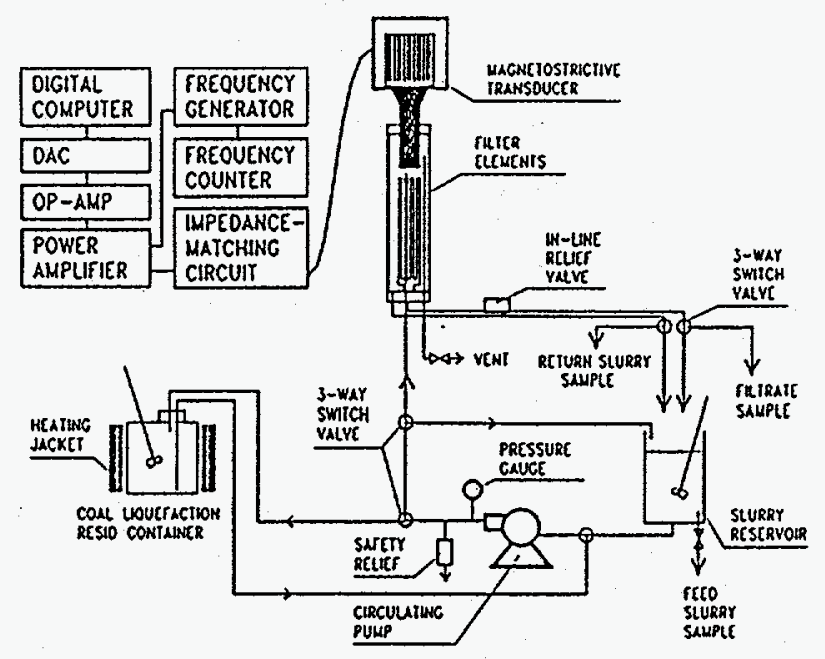

Figure 1. Configuration of the crossflow filtration apparatus.

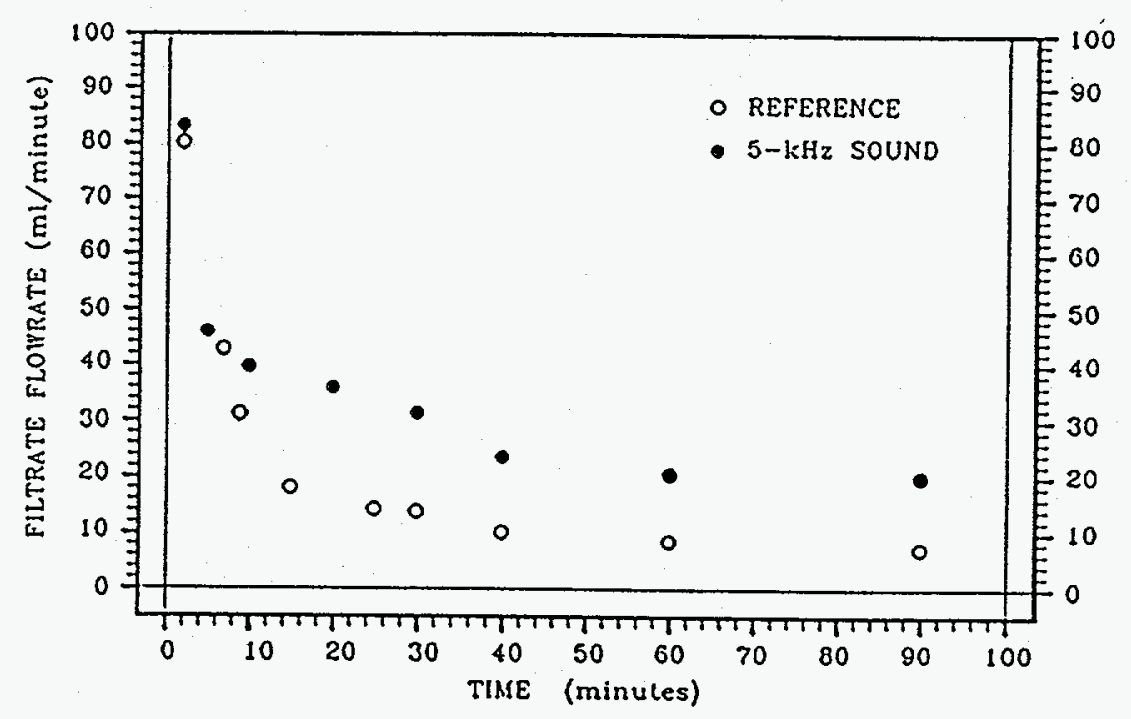

Figure 2. Effect of sonic waves on filtrate flow rates.

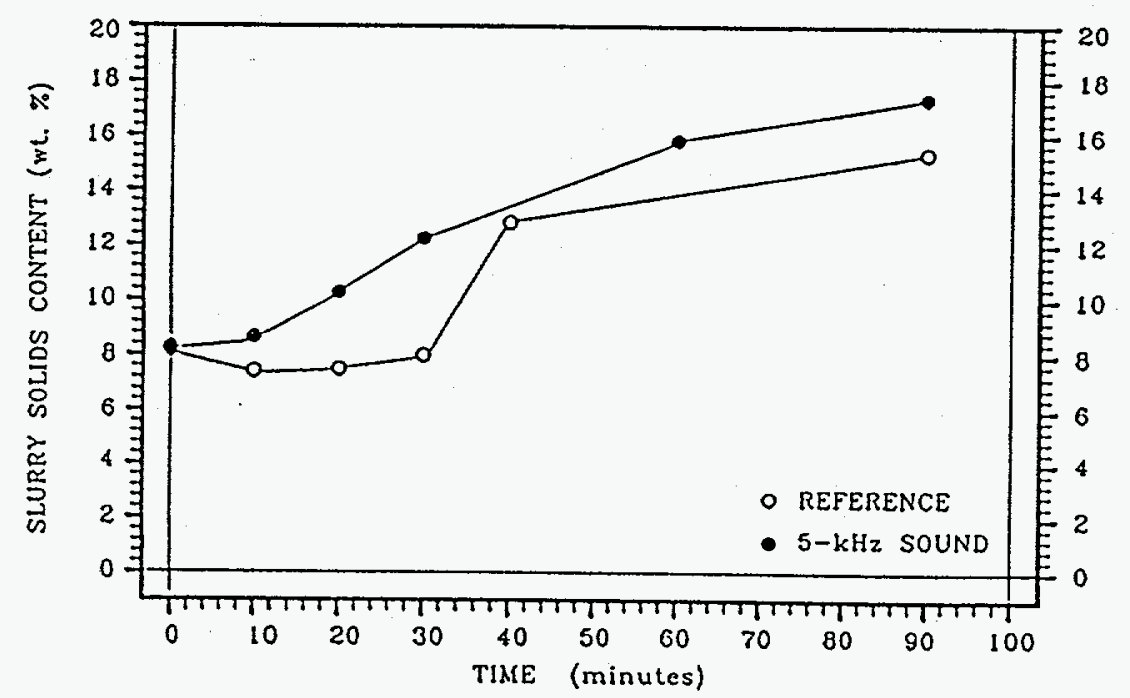

Figure 3. Effect of sonic waves on slurry solids content. 